IdeAs

Idées d'Amériques

$17 \mid 2021$

Villes et culture dans les Amériques

\title{
El Acuerdo de Escazú y los Líderes Sociales en Colombia
}

Felipe Calderón-Valencia

\section{(2) OpenEdition}

1 Journals

Edición electrónica

URL: https://journals.openedition.org/ideas/10366

DOI: 10.4000/ideas.10366

ISSN: 1950-5701

Editor

Institut des Amériques

Referencia electrónica

Felipe Calderón-Valencia, «El Acuerdo de Escazú y los Líderes Sociales en Colombia», IdeAs [En línea], 17 | 2021, Publicado el 01 marzo 2021, consultado el 03 junio 2021. URL: http:// journals.openedition.org/ideas/10366; DOI: https://doi.org/10.4000/ideas.10366

Este documento fue generado automáticamente el 3 junio 2021

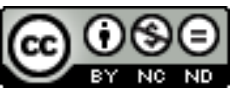

IdeAs - Idées d'Amériques est mis à disposition selon les termes de la licence Creative Commons Attribution - Pas d'Utilisation Commerciale - Pas de Modification 4.0 International. 


\title{
El Acuerdo de Escazú y los Líderes Sociales en Colombia
}

\author{
Felipe Calderón-Valencia
}

\section{Defensores Ambientales ¿Quiénes son?}

1 Los Defensores Ambientales (DA) son un tipo de las lideresas y líderes sociales, son individuos $^{1} \mathrm{u}$ organizaciones que amparan casusas sociales, siendo denunciantes y veedores de la aplicación de las sanciones que merece toda violación a los derechos al territorio y de la naturaleza. Los DA no requieren ejercer su labor de manera remunerada y lo hacen de forma pacífica.

Dicha actividad está ligada a su identidad: los DA son aquellos que hacen. Esto implica, primero, que el reconocimiento a su labor lo hace la comunidad y, segundo, que las autoridades podrían identificarlos por las actividades de liderazgo ambiental que desempeñan. Sin embargo, las autoridades se obstinan en identificarlos por la afiliación o membresía oficial a un grupo u organización. Este es un factor que dificulta su protección y acceso a la justicia. Tristemente, este es un problema derivado de una interpretación errónea de las normas que los protegen (Calderón-Valencia, F. y M. Escobar-Sierra, 2020); es decir, las autoridades niegan el acceso a la justicia de los DA porque se trata de personas que luchan por el territorio y la naturaleza sin tener un contrato de trabajo o sin integrar formalmente una organización para desempeñar esta labor acorde al canon normativo. Las autoridades podrían proteger a los DA por su labor, contrariando el formalismo que los desvía de la recta razón que, paradójicamente, es flexible cuando hablamos de derechos humanos

3 Es por esto que los DA tienen derechos especiales, cuya interpretación debe estar en armonía con la doctrina del sistema interamericano de protección de derechos humanos (Julio Estrada E. y E. Jesús Pérez, 2019). Entonces, el respeto a su vida e integridad física, libertad, seguridad personal y de su entorno familiar, así como a sus bienes, debe ser entendido como una forma de proteger indirectamente el medio ambiente del que hablan el artículo 79 de la Constitución Política de Colombia y la 
Opinión Consultiva OC-23 de 2017 de la Corte Interamericana (Corte IDH, 2018). Igualmente, los DA son los guardianes de los derechos de acceso que trae el Acuerdo de Escazú de 2018 (en adelante, AE). En este orden de ideas, para defender a la naturaleza como causa común a la humanidad, ellos requieren de derechos como: 10 de la Declaración de Río de 1992. Las dinámicas de protección al activismo social y ambiental (ISHR, 2017) ya habían sido promovidas internacionalmente ${ }^{2}$ y regionalmente ${ }^{3}$, pero el $\mathrm{AE}$ es el primer instrumento que define directamente el término DA, de ahí la urgencia que representa su puesta en vigor por el Estado colombiano.

\section{El Acuerdo de Escazú a la deriva} diciembre firmó el documento y hasta ahora no se ha hecho nada para su ratificación. La falta de voluntad política pone en evidencia que su firma fue un gesto meramente retórico, tal y como lo muestra la indiferencia ante los 205 líderes sociales asesinados en este 2020 - 47 eran líderes ambientales, 67 según de Global Witness. Vale decir que esta situación sorprende porque se trata del laissezfairismo social de un gobierno que se eligió para implantar un proyecto político fundado en la seguridad de los colombianos ${ }^{4}$.

Así, dichos homicidios admiten una lectura política porque Colombia dispone de suficientes normas que protegen y caracterizan el activismo en favor de los derechos humanos como una actividad de alto riesgo ${ }^{5}$. Pese a esto, el marco normativo del país no basta para proteger a sus ciudadanos y las normas no pueden ser letra muerta. En Colombia se descuida protegiendo. Particularmente, cuidar a los DA es una postura tardía y el gobierno solo le prestó atención durante la intervención de Michel Forst, Comisionado de Naciones Unidas. A finales del año 2018, su destacada visita provocó que el gobierno Duque expidiera los decretos 660 y 2137.

El lugar que ocuparon los DA en el Decreto 660 está en el artículo 2.4.1.7.1.3. Entre los sujetos protegidos están las "comunidades y organizaciones [...] defensoras de derechos humanos en los territorios, así como sus líderes, lideresas, dirigentes, representantes y activistas". Esto complementa el Decreto 2252 de 2017 que habla de personas "defensoras de derechos humanos que se encuentren en situación de riesgo o amenaza [...]". Sin embargo, queda de la reforma un cierto enfoque corporativista. Con este, la protección de los DA depende de su pertenencia a una organización. Tal formalismo entraba, entre otros, el derecho de acceso a la justicia de los líderes sociales ${ }^{6}$.

11 Contrario a esta evidente dificultad, el derecho ambiental y el constitucionalismo verde (Bernaud V. y F. Calderón-Valencia, 2020) brindan auxilio a la interpretación que pueden hacer los servidores públicos y los mismos DA en favor de sus derechos, aunado a la reciente aparición de la doctrina de los "derechos de la naturaleza" . Primero, existe la "Constitución Ecológica", un subsistema creado por la Corte Constitucional 
Colombiana ${ }^{8}$ y, luego, la Ley 99 de 1993 que creó el Sistema Nacional Ambiental (SINA), un "conjunto de orientaciones, normas, actividades, recursos, programas e instituciones que permiten la puesta en marcha de los principios generales ambientales contenidos en esta Ley". Es decir, antes del AE ya existían herramientas para garantizar la vida de los DA y permitirles ejercer su labor sin que los amenacen, los maten o que los criminalicen. Cuidar los bosques y con ellos el oxígeno que respiramos, los ríos y la diversidad, no es un delito.

\section{Conclusión}

Finalmente, en Colombia son muchos los enemigos de la ratificación del Acuerdo de Escazú, solo porque permite proteger la naturaleza y a los DA como extensión necesaria de esta. Pero, incluso ante esta adversidad, los funcionarios tienen herramientas suficientes para garantizar el derecho de todos al medio ambiente que los líderes sociales protegen con su vida, no solo para Colombia, sino también en favor de la humanidad.

Entonces, garantizar que los DA ejerzan su labor, de forma segura para ellos y su familia y sin restricciones o intimidaciones, es igual a cuidar los derechos al ambiente sano y los que son propios de la naturaleza. Una Constitución Política puede garantizar estos derechos y muchos más, pero si no protege a quienes sirven a tal propósito, no está haciendo nada. Los derechos son abstracciones, ficciones, pero son tangibles las personas y la materialización del deseo de preservar un planeta y recursos para las generaciones futuras.

Es por este motivo que el AE podría dar más soporte al cuidado necesario que requieren los líderes ambientales, especialmente los que defienden una causa común a la humanidad, como el equilibrio de los ecosistemas y el mantenimiento de la biodiversidad.

\section{BIBLIOGRAFÍA}

Asamblea Nacional Constituyente, Constitución Política de Colombia, Gaceta Constitucional $\mathrm{n}^{\circ} 116$ de 20 de julio de 1991, https://www.alcaldiabogota.gov.co/sisjurMantenimiento/normas/ Norma1.jsp?i=4125, consultado el 18 de diciembre 2020.

Bernaud, Valérie, y Calderón-Valencia, Felipe, “Un Exemple de Constitutionnalisme Vert : La Colombie," Revue Française de Droit Constitutionnel, vol. 122, n 2, 2020, p. 321-343. https://doi.org/ 10.3917/rfdc.122.0321, consultado el 18 de diciembre 2020.

Calderón-Valencia, Felipe, y Escobar-Sierra, Manuela, “Defensores Ambientales En Colombia y Razonamiento Abductivo En El Acceso a La Justicia", Veredas Do Direito, vol. 17, n 38, 2020, p. 69112. https://doi.org/https://doi.org/10.18623/rvd.v17i38.1678, consultado el 18 de diciembre 2020. 
CEPAL, Acuerdo Regional sobre el Acceso a la Información, la Participación Pública y el Acceso a la Justicia en Asuntos Ambientales en América Latina y el Caribe, adoptado en Escazú (Costa Rica), el 4 de marzo de 2018, apertura a la firma en la Sede de las Naciones. https://www.cepal.org/es/ organos-subsidiarios/acuerdo-regional-acceso-la-informacion-la-participacion-publica-accesola, consultado el 18 de diciembre 2020.

CIDH, "Personas Defensoras de Derechos Humanos y Líderes Sociales En Colombia”, Washington D. C., 2019. http://www.oas.org/es/cidh/informes/pdfs/DefensoresColombia.pdf, consultado el 18 de diciembre 2020.

Congreso de la República de Colombia, Ley 99 del 1993, Diario Oficial No. 41.146 de 22 de diciembre de 1993. http://www.secretariasenado.gov.co/senado/basedoc/ley_0099_1993.html, consultado el 18 de diciembre 2020.

Corte Constitucional Colombiana, Sentencia T-411 de 1992, M. P.: Alejandro Martínez Caballero.

Corte Constitucional Colombiana, Sentencia T-473 de 2018, M. P.: Alberto Rojas Ríos.

Corte Constitucional Colombiana, Sentencia T-622 de 2016, M. P.: Jorge Iván Palacio Palacio.

Corte IDH, "Informe Anual de La Corte Interamericana de Derechos Humanos 2017", San José, 2018.

Corte IDH, OC-23/17 del 15 de noviembre de 2017, Solicitada por la República de Colombia.

Corte Suprema de Justicia, Sentencia STC 4360-2018 Radicación n.11001-22-03-000-2018-00319-01, M. P.: Luis Armando Tolosa Villabona.

Global Witness, "Defender el mañana. Crisis climática y amenazas contra las personas defensoras de la tierra y del medio ambiente", 29 de julio de 2020. https://www.globalwitness.org/es/ defending-tomorrow-es/, consultado el 25 de noviembre de 2020.

ISHR, “Ley Modelo Para El Reconocimiento y La Protección de Las Personas Defensoras de Derechos Humanos", Ginebra, New York, 2017. https://www.ishr.ch/sites/default/files/ documents/model_law_spanish_january2017_screenversion.pdf, consultado el 18 de diciembre 2020.

Julio Estrada, Elxei, y Jesús Pérez, Edward, “Los Deberes de La Empresa En La Protección Del Derecho a Un Medio Ambiente Sano Según La Jurisprudencia de La Corte Interamericana de Derechos Humanos" in Julián Tole Martínez (ed.), Desafíos Para La Regulación de Los Derechos Humanos y Las Empresas: ¿cómo Lograr Proteger, Respetar y Remediar?, Bogota, Universidad Externado de Colombia, 2019.

OIT, Convenio n 169 de 1989.

ONU, Declaración de Río sobre el Medio Ambiente y el Desarrollo, A/CONF.151/26/Rev.l (Vol. I) (1992). https://documents-dds-ny.un.org/doc/UNDOC/GEN/N92/836/58/pdf/N9283658.pdf? OpenElement, consultado el 18 de diciembre 2020.

Presidencia de la República de Colombia, Decreto 2137 de 2018, Diario Oficial nº 50.782 de 19 de Noviembre 2018, Bogotá: Departamento Administrativo de la Función Pública, 2018. https:// www.funcionpublica.gov.co/eva/gestornormativo/norma.php?i=89499, consultado el 18 de diciembre 2020.

Presidencia de la República de Colombia, Decreto 2252 de 2017, Diario Oficial n 50.461 de 29 de diciembre de 2017 (2017). https://www.funcionpublica.gov.co/eva/gestornormativo/norma.php? $\underline{\mathrm{i}=85059}$, consultado el 18 de diciembre 2020 . 
Presidencia de la República de Colombia, Decreto 660 de 2018, Diario Oficial n 50.567 de 17 de abril 2018 (2018). https://www.mininterior.gov.co/la-institucion/normatividad/decretonumero-660-de-2018, consultado el 18 de diciembre 2020.

UN, Resolución A/RES/53/144, Declaración sobre el derecho y el deber de los individuos, los grupos y las instituciones de promover y proteger los derechos humanos y las libertades fundamentales universalmente reconocidos, 1999. https://documents-dds-ny.un.org/doc/ UNDOC/GEN/N99/770/89/PDF/N9977089.pdf?OpenElement, consultado el 18 de diciembre 2020.

\section{NOTAS}

1. Esto incluye activistas ambientales y periodistas, así como fotógrafos, informantes.

2. Ver OIT, Convenio n¹69 de 1989; UN, Resolution A/RES/53/144 (Declaración sobre el derecho y el deber de los individuos, los grupos y las instituciones de promover y proteger los derechos humanos y las libertades fundamentales universalmente reconocidos).

3. Ver CIDH, "Personas Defensoras de Derechos Humanos y Líderes Sociales En Colombia."

4. "No toda es vigilia la de los ojos abiertos": El gobierno de Juan Manuel Santos Calderón hizo algo muy parecido porque se encargó de negociarlo, torpedeando su proceso y negándose a firmarlo.

5. Ver Corte Constitucional Colombiana, Sentencia T-473 de 2018 (M. P.: Alberto Rojas Ríos).

6. Pese a esto, debe señalarse que el Decreto 660 abre la participación de los DA; v. artículo 2.4.1.7.1.7, num.13.

7. Corte Constitucional Colombiana, Sentencia T-622 de 2016 (M. P.: Jorge Iván Palacio Palacio); Corte Suprema de Justicia, Sentencia STC 4360-2018 Radicación n.11001-22-03-000-2018-00319-01 (M. P.: Luis Armando Tolosa Villabona).

8. Corte Constitucional Colombiana, Sentencia T-411 de 1992 (M. P.: Alejandro Martínez Caballero).

\section{AUTOR}

\section{FELIPE CALDERÓN-VALENCIA}

Felipe Calderón-Valencia es abogado, Doctor en derecho de la Universidad Panthéon-Assas (Paris II), Docente-investigador y Coordinador del Centro de Investigaciones Jurídicas (CIJ) de la Universidad de Medellín (Colombia) ; http://orcid.org/0000-0001-7384-7470; felipecalderonvalencia@gmail.com. 